\title{
Frequency of Chronic Venous Disease among Nurses
}

\author{
Cendy Martanegara ${ }^{1}$, RA Retno Ekowati ${ }^{2}$, Teguh Marfen Djajakusumah ${ }^{3}$ \\ ${ }^{1}$ Faculty of Medicine, Universitas Padjadjaran, ${ }^{2}$ Department of Biomolecular, Faculty of Medicine, \\ Universitas Padjadjaran, ${ }^{3}$ Department of Surgery, Faculty of Medicine, Universitas Padjadjaran / \\ Dr. Hasan Sadikin General Hospital Bandung
}

\begin{abstract}
Background: Chronic vein diseases are quite common and its prevalence is also quite high in community. One of the risk factors is occupation with prolonged standing. Quality of life and work efficacy may become risk factors. This disease has not received any special consideration and response.

Methods: This is a cross-sectional study performed on nurses working in Dr. Hasan Sadikin General Hospital Bandung ( $n=98$; women=76, men=22). The study was conducted in November 2012 through collecting data on prevalence, risk factors, and clinical symptoms by using questionnaire. Chronic venous disease was observed by direct inspection in lower extremities. Diagnosis was concluded according to the Clinical Etiology Anatomy Pathophysiological criteria.

Results: There was a high frequency, i.e. $86.7 \%(n=71)$, of chronic venous disease among nurses, with the age group of $20-29$ years old (34.1\%) as the age group that was mostly affected. Among female nurses, almost all of them experienced the disease (93.4\%; $n=71)$. Clinical symptoms felt by most nurses were heavy feeling on legs (82.3\%) and cramps (55.3\%).

Conclusion: The frequency of chronic venous disease among nurses is high, $86.7 \%$ and almost all of the female nurses suffer from the disease. The high frequency in females could be caused by risk factors such as parity and hormonal contraception. Those who are mostly affected by the disease are within range of age 20-29 years old of age. Heavy legs and cramps are the most frequent clinical symptoms felt.
\end{abstract}

Keywords: Chronic vein disease, frequency, nurses

\section{Introduction}

There are several risk factors for chronic venous disease (CVD) which can be endogenous or exogenous. Endogenous risk factors are age, sex, multiple pregnancies, hormonal contraception, obesity, and exogenous risk factor are prolonged standing, high temperature and humidity.1 Prevalence in the community is also high, between 40$76 \% .1$ Some studies revealed that the clinical symptoms, such as heavy legs, cramps, feeling burnt or hot, and itch can affect psychological, financial, and work efficiency.2,3

A study in Austria revealed a high prevalence of chronic venous disease among hospital employees and found a positive correlation between presence of chronic venous disease and mean periods of standing each day. The samples in this study were medical doctors and nurses, medical technician assistants, secretaries, scientific staff, cleaners and utility workers, with the highest prevalence was among medical doctors and nurses. 4

Thereare no published data about frequency of chronic venous disease in Indonesia, also in Dr. Hasan Sadikin General Hospital Bandung which is the national hospital that may indicate a high workload among the hospital employees. The samples included in this study were only nurses. The aim of this study was to determine the frequency of chronic venous disease among nurses in Dr. Hasan Sadikin General Hospital Bandung.

\section{Methods}

The study population were randomly selected from nurses working in Dr. Hasan Sadikin Hospital Bandung from six different places; emergency department, central operating theatre, outpatient surgery clinic, and surgical ward. The total participants were 76 female and 22 male nurses.

Correspondence: Cendy Martanegara, Faculty of Medicine, Universitas Padjadjaran, Jalan Raya Bandung-Sumedang Km.21, Jatinangor, Sumedang, Indonesia, Phone: +628985066418 Email: cmartanegara@gmail.com 
Table 1 Clinical part of CEAP classification ${ }^{5}$

\begin{tabular}{ll}
\hline C0 & No visible or palpable sign of CVD \\
C1 & Telangiectasis or reticular veins \\
C2 & Varicose vein \\
C3 & Edema \\
C4a & Skin changes; pigmentation or \\
& eczema \\
C4b & Lipodermatosis or atrophie blanchie \\
C5 & Skin changes with healed ulceration \\
C6 & Active ulceration \\
\hline
\end{tabular}

All participants agreed to sign the informed consent after receiving explanation about the study and procedure, and then filled the questionnaire regarding risk factors such as age, length of work in years, parity, hormonal contraceptive, and Body Mass Index (BMI). Next, the participant was examined for their lower extremities and stand-up for minimum 30 seconds. All examinations were performed by one examiner who classified the findings according to the Clinical Etiology Anatomy Pathophysiological (CEAP) classification (Table 1). Participants were also asked for clinical symptoms, such as heavy feeling on legs, burning or hot sensations, edema, pruritus, and cramp. The data were presented as frequency analysis distribution and was statistically analyzed using computer.

\section{Results}

Confirmation of the presence of CVD was performed by visual inspection of the lower extremities, as well as obtaining information regarding signs and symptoms of CVD (Table 2). From the entire clinical symptoms, heavy legs and cramps were the most symptoms felt by the nurses with CVD. There were

Table 2 Clinical symptoms

\begin{tabular}{lcc}
\hline \multirow{2}{*}{ Symptoms } & \multicolumn{2}{c}{ Chronic Venous Disease } \\
\cline { 2 - 3 } & Occurrence & Absence \\
\hline Heavy Legs & 70 & 2 \\
Burning & 8 & 0 \\
Edema & 2 & 0 \\
Pruritus & 8 & 1 \\
Cramp & 47 & 0 \\
\hline
\end{tabular}

Table 3 Study Sample Characteristics

\begin{tabular}{lc}
\hline \multicolumn{1}{c}{ Characteristics } & n (\%) \\
\hline Sex & $22(22.4)$ \\
Male & $76(77.6)$ \\
Female & \\
Age (years) & $37(37.8)$ \\
$20-29$ & $26(26.5)$ \\
$30-39$ & $18(18.4)$ \\
$40-49$ & $17(17.3)$ \\
$50-59$ & \\
Duration of works (years) & $46(46.9)$ \\
$1-10$ & $24(24.5)$ \\
$11-20$ & $19(19.4)$ \\
$21-30$ & $9(9.2)$ \\
$31-40$ &
\end{tabular}

$70(82.4 \%)$ nurses who felt heavy legs and $47(55.3 \%)$ felt cramps. Only $8(9.4 \%)$ felt burning and pruritus, and $2(2.4 \%)$ had edema.

The characteristics were of 98 nurses, consisting of $76(77.6 \%)$ female and 22 $(22.4 \%)$ male. The range of age was 22 to 56 years, with the mean age 34 years (SD 10.95). As regards duration of work, the range was between 1 to 36 years with mean of duration 11 years (SD 10.4) (Table 3)

The CVD was present in themajority (86.7\%; $n=85$ ) of nurses in this hospital (Figure 1), among both sexes indeed themajority suffered ofthe disease: $71(93.4 \%)$ werefemale nurses and $14(63.6 \%)$ were male nurses.

Table 4 evaluated several risk factors. The data showed more than one third of the nurses with CVD were in the range of age 20-29 years and only a minority were of older age. As regards the duration of work, the majority of them has worked less than 10 years $(43.5 \%)$. Among female nurses with this disease only a minority $(8.2 \% ; n=7)$ used hormonal contraception. When evaluation of thenumber of parity was obtained, among the female nurses who suffered CVD there were nulliparous and primiparous $(52.6 \%$; $n=40)$ and less multiparous in female $(43.7 \% ; n=31)$. Regarding Body Mass Index (BMI), only the minority $(7.1 \%$; $n=6)$ of all nurses with CVD was classified into obese. 
Table 4 Risk Factors of CVD

\begin{tabular}{lcc}
\hline \multirow{2}{*}{ Risk Factors } & \multicolumn{2}{c}{ Chronic Venous Disease } \\
\cline { 2 - 3 } & Occurrence & Absence \\
\hline Age (years old) & 29 & 8 \\
$20-29$ & 23 & 3 \\
$30-39$ & 17 & 1 \\
$40-49$ & 16 & 1 \\
$50-59$ & & \\
Duration of work (years) & 37 & 9 \\
$1-10$ & 21 & 3 \\
$11-20$ & 19 & 0 \\
$21-30$ & 8 & 1 \\
$31-40$ & 6 & 0 \\
Obesity (BMI >30) & 7 & 0 \\
Hormonal contraception & 31 & 0 \\
Multipara & & \\
\hline
\end{tabular}

\section{Discussions}

This study aimed to determine the frequency of CVD among nurses. The presence of CVD was confirmed by visual inspection as well as evaluation of signs and symptoms of CVD among the patients. Most of the nurses with CVD felt heavy legs $(82.3 \%, n=70)$ and cramps $(55.2 \%, n=40)$. These findings were slightly different compared to the study of Ziegler et al. ${ }^{4}$, where heavy legs and edema are the most occuring common symptoms.

There was a high frequency of CVD among nurses working in this hospital, of which the majority experienced this disease. This high frequency might also be influenced by the work environmental risk, such as a higher temperature and humidity. There was also possibility that higher orthostatic burdens were present due to the workload, since Dr. Hasan Sadikin General Hospital Bandung is the reference hospital in the province. 4,6

From the total of 85 nurses with CVD, the majority was found in women. This finding is similar with the result from a study of Tuchsen et al. ${ }^{7}$ and Carpantier et al. ${ }^{8}$ where CVD occurs predominantly in women. Since the majority of nurses are women, therefore there was an imbalance proportion of population in this study. When the data was calculated separately between sexes, the frequency of occurrence was found in more than half of population of both sexes.
When evaluation of risk factors among female nurses was obtained, parity did not become risk factors among these women. This is contradictive with a previous study which stated that this factor was associated with this disease. ${ }^{1}$ Within this study, there were less multiparous women. Moreover, there was other contradictive risk factors found compared to a study conducted by BeebeDimmer et al. ${ }^{1}$. Older age and higher BMI did not become risk factors among these women. More nurses suffered from this disease at a younger age, and a majority had normal BMI. Therefore the most possible risk factor may come from the orthostatic burdens as stated above. ${ }^{4,6}$

Some research found that hormonal contraception could be the risk factors. 1 This study had a contradictive result, where only a minority of nurses suffering from this disease used hormonal contraception. The result agrees with Kostas et al.,9 who found that from 71 women nurses with CVD 34 (47.8\%) used contraception; among them a minority used hormonal contraception.

In conclusion, this high frequency of CVD should become a concern of the nurses. They should pay more attention to work-related health risk. Risk of CVD could be lowered with more active life style; such as more sports and little simple movements of lower extremities after long standing. Also for nurses who already had CVD they should seek for treatment (e.g.: 


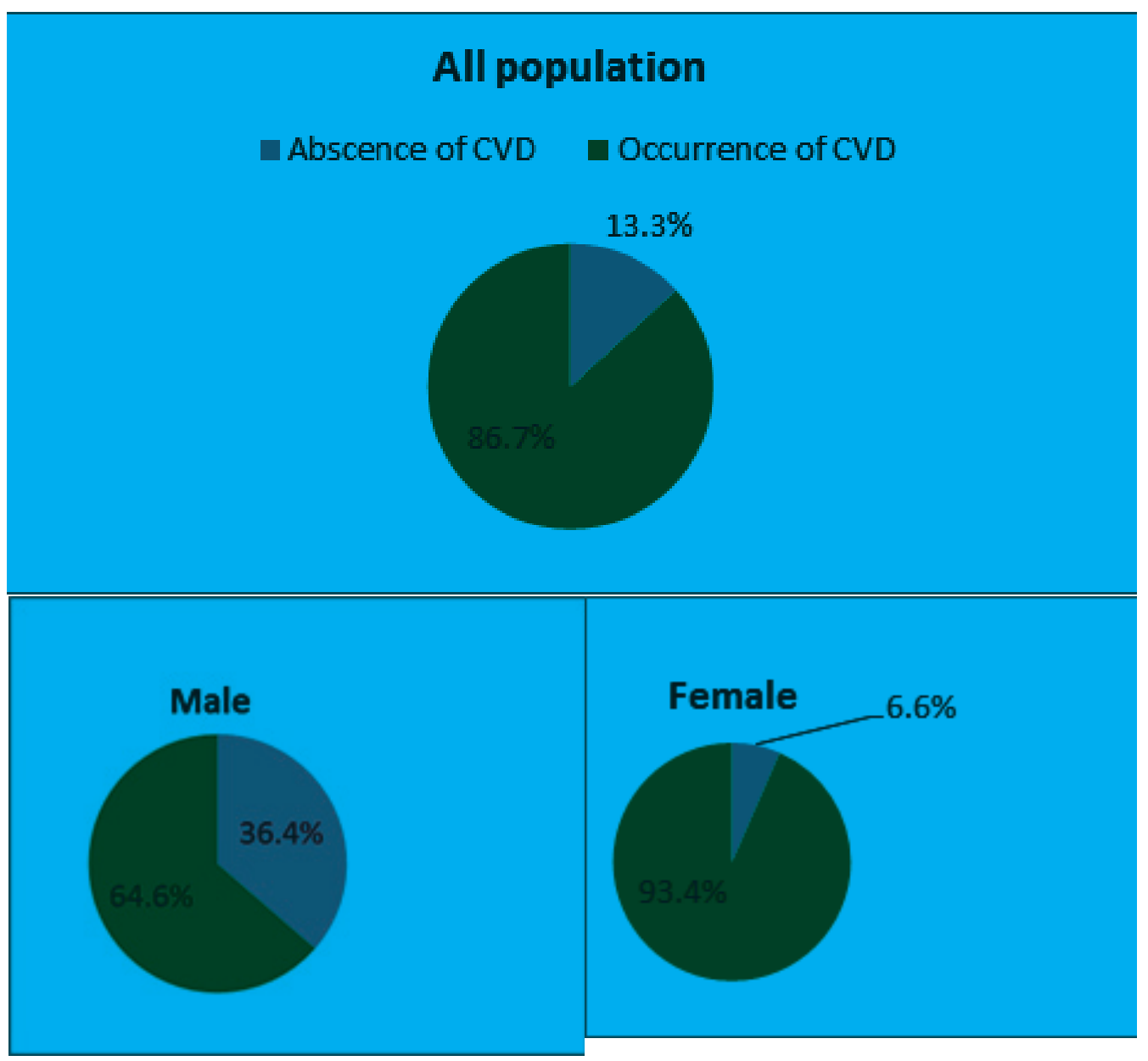

Figure 1 Frequency of Chronic Venous Disease

schlerotherapy injection) or use compression stockings.

\section{References}

1. Beebe-Dimmer JL, Pfeifer JR, Engle JS, Schottenfeld D. The epidemiology of chronic venous insufficiency and varicose veins. Ann Epidemiol. 2005;15(3):175-84.

2. Rabe E, Pannier F. Societal costs of chronic venous disease in CEAP C4, C5, C6 disease. Phlebology. 2010;25 (Suppl 1):64-7.

3. Sritharan K, Lane TRA, Davies AH. The burden of depression in patients with symptomatic varicose veins. Eur J Vasc Endovasc Surg. 2012;43(4):480-4.

4. Ziegler S, Eckhardt G, Stöger R, Machula J, Rüdiger HW. High prevalence of chronic venous disease in hospital employees. Wien KlinWochenschr.2003:115(15-16):575-9.

5. Pappas PJ, Lal BK, Padberg FT, Zickler
RW, Duran WN. Handbook of venous disorders: Edward Arnold Ltd.; 2009. [downloaded in 6 April 2012] Available at: http://www.hoddereducation.com.

6. Kroeger K, Ose C, Rudofsky G, Roesener J, Hirche $\mathrm{H}$. Risk factors for varicose veins. Int Angiol. 2004;23(1):29-34.

7. Tuchsen F, Krause N, Hannerz H, Burr $\mathrm{H}$, Kristensen TS. Standing at work and varicose veins. Scand J Work Environ Health. 2000;26(5):414-20.

8. Carpentier PH, Maricq HR, Biro C, PoncotMakinen CO, Franco A. Prevalence, risk factors, and clinical patterns of chronic venous disorders of lower limbs: a population-based study in France. J Vasc Surg. 2004;40(4):650-9

9. Kostas TI, Ioannou CV, Drygiannakis I, Georgakarakos E, Kounos C, Tsetis D, et al. Chronic venous disease progression and modification of predisposing factors. J Vasc Surg .2010;51(4):900-7. 
10. Jawien A. The influence of environmental factors in chronic venous insufficiency.

Angiology. 2003;54 (Suppl 1):S19-31. 